\title{
Design Consideration of a High-Speed Integrated Permanent Magnet Machine and its Drive System
}

\author{
Xu Deng, Simon Lambert, Barrie Mecrow and Mohamed Awad S Mohamed
}

\begin{abstract}
This paper presents the design consideration of a high-speed synchronous drive with integrated magnetics of the grid connected LCL filter. Consisting of the combination mechanical, thermal and electrical aspects of an electric drive system this integrated drive claiming to exhibit significant benefits over traditional electrical drive systems as well as cost reductions. Four major technical issues related to this integrated drive are introduced in this paper, including integrating magnetics of the grid connected filters in the machine with minimized coupling effects, investigating a novel winding connection method to manage extra terminals induced by filters, a compact power electronics design with $\mathrm{SiC}$ devices and thermal management considering both electrical machine and power electronics.
\end{abstract}

Index Terms-Bus bar, LCL filter, Integrated Motor Drive (IMD), synchronous machine, silicon carbide (SiC), winding connection, thermal management.

\section{INTRODUCTION}

$\mathrm{W}$ ith increased demand in electric drives applications for higher power density, higher efficiency and higher temperature operation, integrated motor drives are gaining greater interest in automotive, aerospace and other specialist applications[1,2].

The traditional physically separated motor and drive systems, consisting of discrete subsystems, have shifted to more compactly integrated, higher power dense, motor-drive combinations in the past two decades and this concept has been defined as Integrated Motor Drive (IMD) [3, 4]. The IMD concepts have recently received greater attention in literature due to lots of advantages they provided, and are increasingly seen as the standard for future automotive applications [5-7]. In general the most significant advantages include the ability to replace direct on line machines with variable speed drives, lower EMI [8], less loss and higher power density.

High-speed electrical machines are required to achieve high power density with smaller machine volume and smaller passive components. Grid connected AC drives usually have front-end filters to ensure low current Total Harmonic Distortion (THD) and to make the drives more robust against

$\mathrm{Xu}$ Deng is with Electrical Power Group, School of Engineering, Newcastle University, NE1 7RU, UK. (e-mail: xu.deng@ncl.ac.uk)

Simon Lambert is with Electrical Power Group, School of Engineering, Newcastle University, NE1 7RU, UK. (e-mail: simon.lambert@ncl.ac.uk)

Barrie Mecrow is with Electrical Power Group, School of Engineering, Newcastle University, NE1 7RU, UK. (e-mail:barrie.mecrow@ncl.ac.uk)

Mohamed Awad S Mohamed is with Electrical Power Group, School of Engineering, Newcastle University, NE1 7RU, UK. (e-mail: mohamed.mohamed@ncl.ac.uk) unbalanced supply voltages. Considerable works have been done to reduce the size of passive components. For all the filter configurations, LCL filter is the most popular choice in grid-connected power converter systems for its excellent performance [9-11].

One of the major factors in determining what power density of an integrated drive can be achieved is the component selection. Since it determines the control frequency, the cooling method, the size of the passive components and all the auxiliary drive circuits, the selection of switching devices effects the power density most significantly. Recently the wide bandgap (WBG) technology such as silicon carbide $(\mathrm{SiC})$ has created the best opportunity for increasing the power density due to its wider voltage range, higher thermal conductivity, higher operating temperatures and higher current density than all-Si devices $[12,13]$.

A variety of integration approaches for power electronic have been investigated in the last decade [14, 15]. These approaches are ranging from a crude mounting of the power electronics on the machine housing to a modular structural and functional integration of the power electronics inside the machine housing. However, the power electronics is placed close to heat sources in the machine - copper windings, back iron and rotor; which may cause irreparable damage to the less robust converter unit. Therefore, the structural integration of the machine and the power electronics give rise to a design problem which demands reasonable thermal management.

Integrated drives not only physically integrate the various components of the drive (power electronic devices, filter components etc.) they must also integrate the various connections between these components. Although few articles report this integration it is nevertheless of equal importance to the integration of the active and passive parts.

In this paper, a $34.0 \mathrm{~kW} 25000 \mathrm{r} / \mathrm{min}$ integrated Permanent Magnet (PM) machine and its drive system is proposed. The magnetics of the grid connected LCL filter are integrated in the machine. FE analysis is carried out to minimize the coupling effect between two inductors from the same phase. Afterwards, a novel 4-layer bus bar solution is proposed to manage extra terminals induced by the LCL filter and all the electrical connections to the front-end mounted power electronics. A modular functional and structural power electronics design with $\mathrm{SiC}$ MOSFETs is then proposed. A thermal management approach considering cooling of both machine and high power density power electronics is also proposed in the end of this paper. 


\section{INTEGRATION OF THE GRID CONNECTED FILTER}

Different integration methods for magnetic filter elements have been carried out and the selective method is called integrated double slot machine (IDSM). The integration of solely drive side inductors (L2) achieves lower volume and losses compared to a traditional discrete 3-phase drive side inductors by $86 \%$ and $22 \%$ respectively. For the selective method, the stator lamination of the original PM machine was modified to double as 3-phase LCL filter inductors integrated into the machine structure [16].
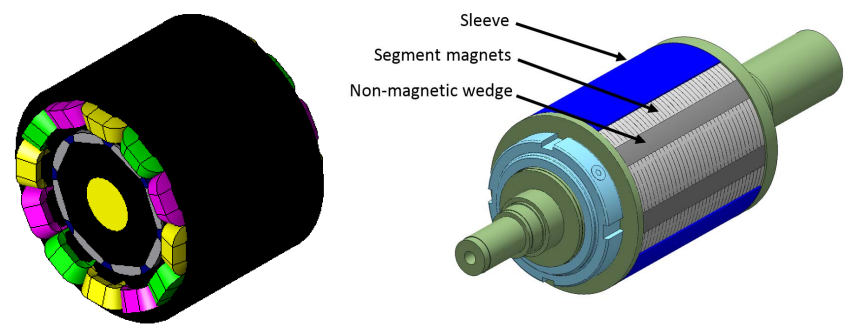

Fig. 1. Original design of the PM machine.

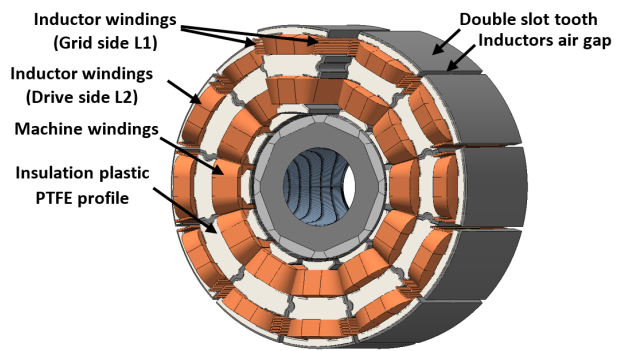

Fig. 2. The integrated double slot machine.

Fig. 1 shows the original structure of the PM machine. Fig. 2 gives the 3D model of the IDSM. The advantage of the proposed IDSM stator geometry is to limit the interaction between the magnetic fields induced by filter inductors and the magnetic fields in the core back induced by the permanent magnets. Since the integration of three-phase drive side inductors (L2) was achieved as presented in [16], further work has been carried out to integrate the grid side inductors (L1) of input LCL filter. The specifications of the drive and LCL filter are given in Table I.

TABLE I

SPECIFICATIONS OF DRIVE AND LCL FILTER MAGNETIC COMPONENTS

\begin{tabular}{|c|c|c|}
\hline \multicolumn{2}{|c|}{ Drive input power (kW) } & 38 \\
\hline \multicolumn{2}{|c|}{ Grid input current (A RMS) } & 53 \\
\hline \multicolumn{2}{|c|}{ Machine Pole number } & 8 \\
\hline \multicolumn{2}{|c|}{ Machine speed(r/min) } & 25000 \\
\hline \multicolumn{2}{|c|}{ Switching frequency (kHz) } & 40 \\
\hline \multirow{2}{*}{$\begin{array}{c}\text { Magnetic inductances of } \\
\text { LCL filter }(\boldsymbol{\mu} \mathrm{H}) \text { per phase }\end{array}$} & $\mathbf{L 1}$ (Grid side) & 5 \\
\cline { 2 - 3 } & $\mathbf{L 2}$ (Drive side) & 160 \\
\hline
\end{tabular}

The integrated geometry of filter inductors is intended to minimize the volume of filter and combine it with the machine structure in a single envelope. As coils of both inductors L1 and L2 of the LCL filter share the same outer slots - and hence magnetic paths -different pole combinations for L1 and L2 have been simulated using FE analysis to investigate the degree of undesired mutual coupling between L1 and L2. Simulation results are shown in Fig. 3. Keeping the drive side inductor as 10 pole and varying the pole number of grid side inductor, coupling effects of different pole number combinations can be easily compared. Current is injected to drive side inductor L2, the induced voltage of drive side and grid side inductors are achieved. One combination shows superior performance in Fig. 3(d), which is the 16 pole and 14 pole combination, there is very tiny voltage can be induced in L1, thus this combination is selected as the optimum design. The machine back-EMF before and after the filter integration is then compared in Fig. 4 , which shows the integration does not affect the operation of the PM machine.

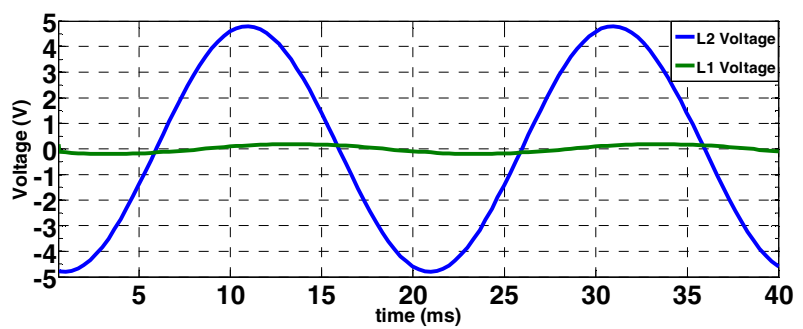

(a) L1 is 2 pole and L2 is 10 pole

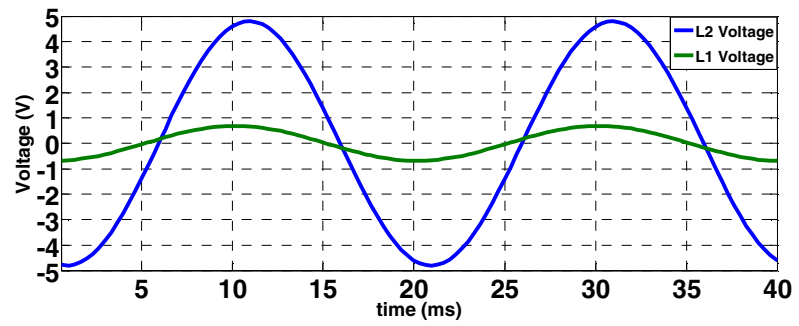

(b) L1 is 10 pole and L2 is 10 pole

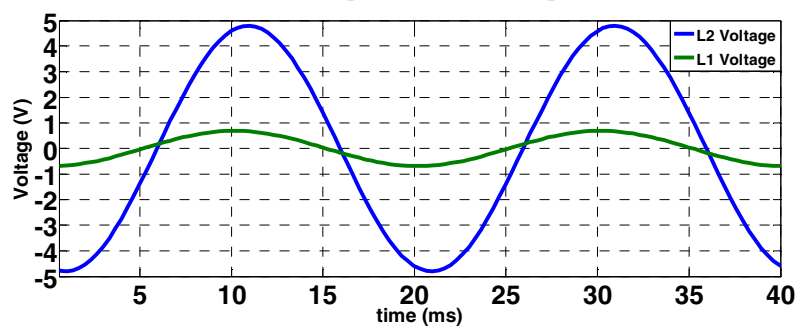

(c) $\mathrm{L} 1$ is 14 pole and L2 is 10 pole

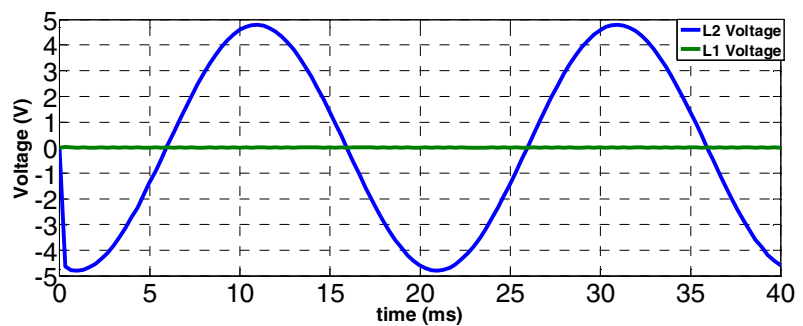

(d) L1 is 16 pole and L2 is 10 pole

Fig. 3. Mutual-coupling investigation between integrated filter inductors at different number of poles in the stator

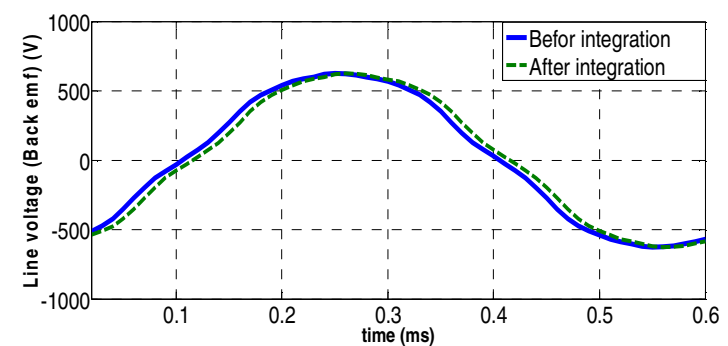

Fig. 4. The original machine back-EMF line voltage before and after integration. 


\section{WINDING CONNECTION SOLUTION}

Fig. 5 shows the winding arrangement of the integrated motor drive. For the three-phase 12/8 permanent magnet synchronous machine, there are twelve main phase windings, and each phase has four concentrated windings connected in parallel. Three phase LCL filters are designed, and each grid/ drive side inductor consists of four concentrated coils. Therefore, there are 36 distributed coils in total, which means a total of 72 winding terminals which need to be connected and routed. The coil specifications are given in Table II.

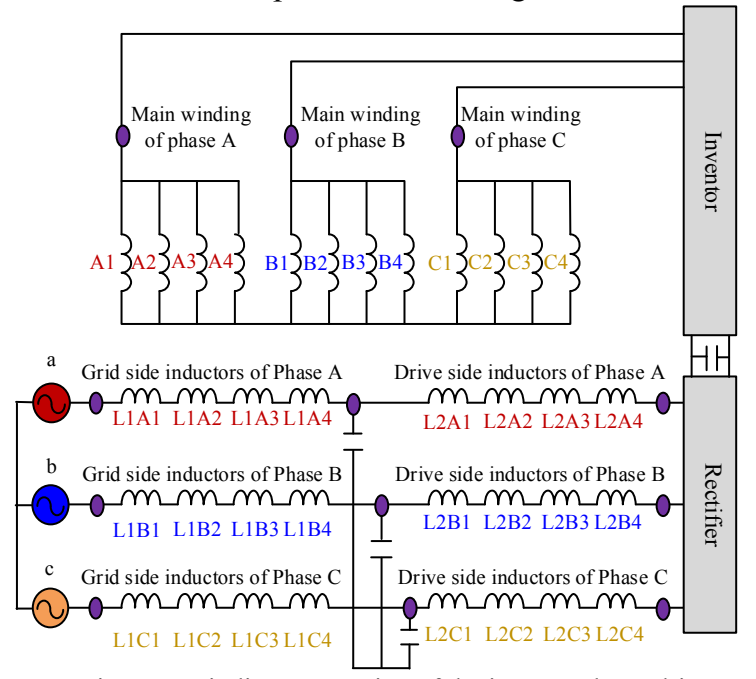

Fig. 5. Winding connection of the integrated PM drive.

TABLE II

WINDING CONFIGURATIONS FOR MACHINE COILS

\begin{tabular}{|c|c|c|c|}
\hline \multirow{2}{*}{$\begin{array}{c}\text { Integrated Motor } \\
\text { Parameters }\end{array}$} & $\begin{array}{c}\text { Base machine } \\
\text { windings }\end{array}$ & \multicolumn{2}{|c|}{ LCL Filter inductor windings } \\
\cline { 3 - 4 } & L1 (Grid side) & L2 (Drive side) \\
\hline $\begin{array}{c}\text { Type of Copper } \\
\text { Wire }\end{array}$ & Litz wire & $\begin{array}{c}\text { Stranded solid } \\
\text { wire }\end{array}$ & $\begin{array}{c}\text { Stranded solid } \\
\text { wire }\end{array}$ \\
\hline Winding Type & Concentrated & Concentrated & Concentrated \\
\hline Coil Connection & Parallel & Series & Series \\
\hline $\begin{array}{c}\text { Number of } \\
\text { Turns/Phase }\end{array}$ & $\begin{array}{c}36 \text { per coil, } 4 \text { coils } \\
\text { in parallel per } \\
\text { phase }(144)\end{array}$ & $\begin{array}{c}1 \text { per coil, } 4 \text { coils } \\
\text { in series per phase } \\
(4)\end{array}$ & $\begin{array}{c}7 \text { per coil, } 4 \text { coils } \\
\text { in peries per phase } \\
(28)\end{array}$ \\
\hline $\begin{array}{c}\text { Conductor } \\
\text { diameter }\end{array}$ & $\begin{array}{c}20 \text { strands } \times 30 \\
\text { AWG }\end{array}$ & $\begin{array}{c}6 \text { Strands } \times 18 \\
\text { AWG }\end{array}$ & $\begin{array}{c}6 \text { Strands } \times 18 \\
\text { AWG }\end{array}$ \\
\hline $\begin{array}{c}\text { Number of poles } \\
\text { in the stator }\end{array}$ & 8 & 16 & 10 \\
\hline
\end{tabular}

However, as the stator diameter of the prototype is only $138 \mathrm{~mm}$, radial extension is undesirable (due to increasing volume by a square factor) and axial extension should be kept to a minimum to maintain high power density. The space is too limited to connect all the windings inside the machine housing using the wire or flying leads. Therefore, the winding interconnects need to be connected on a planar power board.

Some PCB solutions has been considered in [17], but due to all the manufacture and axial length limitations of the PCB solutions, a copper bus bar design is proposed. As shown in bus bars are embedded into grooves in $4 \mathrm{~mm}$ thick PTFE (Poly Tetra Fluoro Ethylene) boards for isolation and mechanical fixing. The dielectric strength of the PTFE is $80 \mathrm{MV} / \mathrm{m}$ [18]. As a guide to manufacturing limitations, the minimum width of the barrier between two bus bars in one layer is $1.0 \mathrm{~mm}$, and the minimum thickness between two bus bars on two adjacent layers is also $1.0 \mathrm{~mm}$ giving an insulation breakdown voltage well in excess of the working voltages of the drive.

Four layer bus bars are illustrated layer by layer in Fig. 6 . The first layer is next to machine. Grid side inductors, threephase windings and half of the neutral point bus bars are arranged in this layer. Four connection holes are designed on three-phase winding bus bars to connect each of the four litz wires in one phase individually. There are $3 \mathrm{~mm}$ thick grooves integrated on the $4 \mathrm{~mm}$ PTFE board, and $1 \mathrm{~mm}$ thick PTFE is reserved on bottom for isolation between bus bar layer 1 and the machine. Drive side inductors and half of the neutral point bus bars are arranged in layer 2 . The rest two layers are to connect internal inductors and main windings with external three-phase power, filter capacitors, the rectifier and the inverter according to twelve purple connection points in Fig. 5. The assembly process and full assembled bus bars are shown in Fig. 7.

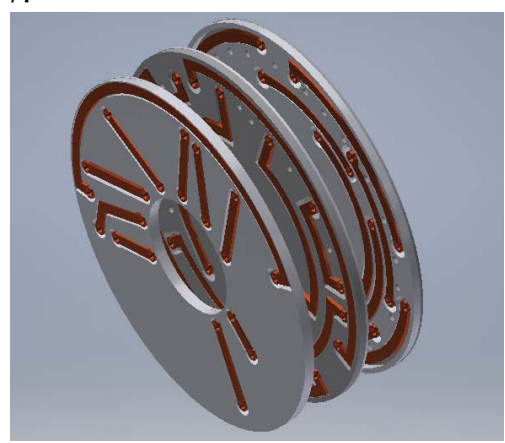

(a) $1^{\text {st }}$ to $3^{\text {rd }}$ layer bus bars

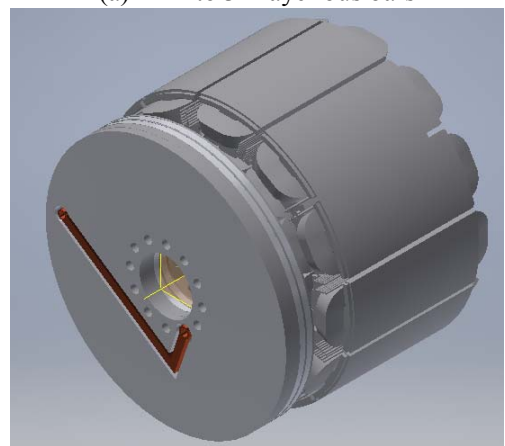

(b) Busbars assembled with machine

Fig. 6. 3D representation of bus bars.

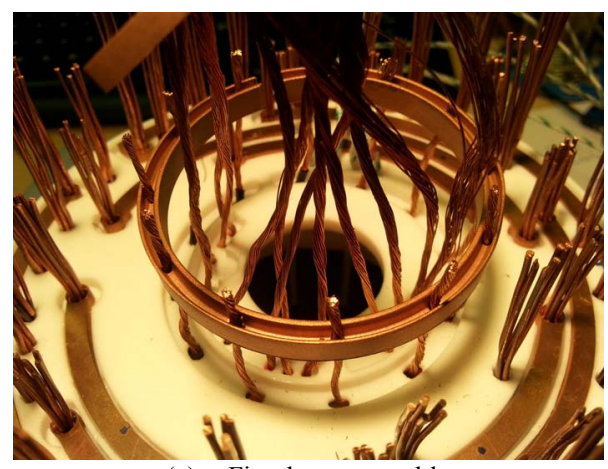

(a) First layer assembly 


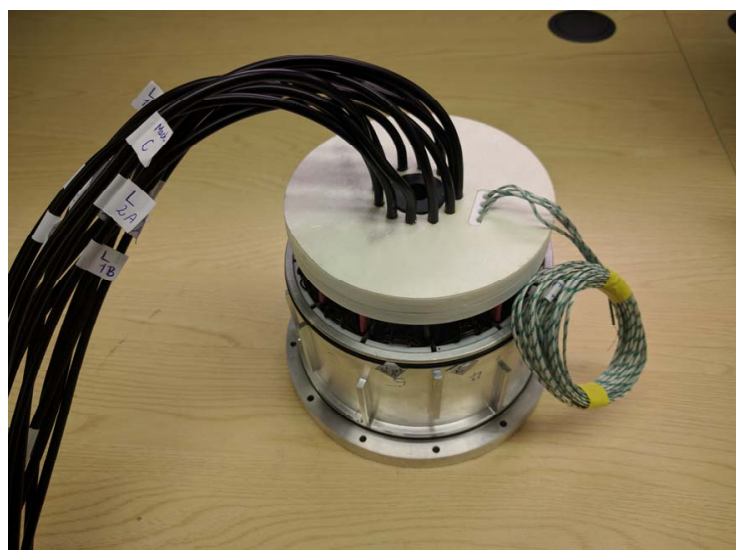

(b) Full assembly

Fig. 7. Bus bars assembly.

\section{INTEGRATION OF POWER ELECTRONICS}

The power electronics of this integrated drive consists of six main parts which are a resolver for rotor position measurement, LCL filter capacitors, DC link capacitors, gate drivers, current and voltage transducers and high frequency SiC MOSFETs. Each individual part of the power electronics has shown in Fig. 8. Full assembly model is shown in Fig. 9.

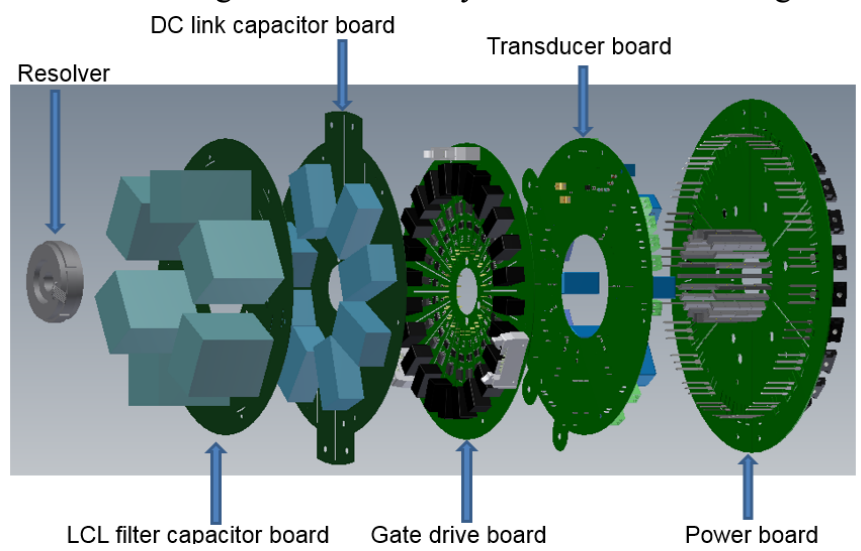

Fig. 8. Constitution of power electronics in the integrated drive.
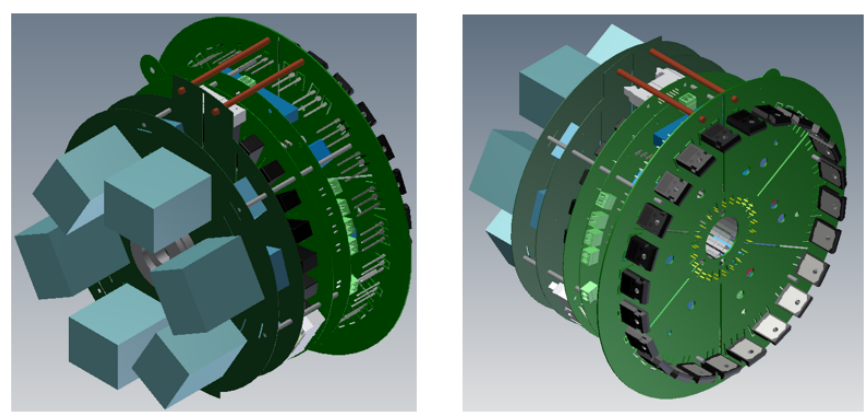

Fig. 9. Full assembly model of the power electronics in the integrated drive.

There are 24 SiC MOSFETs distributed evenly along the edge of the power board. They will be place on the cooling jacket to dissipate the heat from high frequency switching. Each $\mathrm{SiC}$ device can handle 60A continuous drain current, therefore two of them are connected in parallel to provide higher current-carrying capability. In addition, 72 legs of 24
SiC devices will provide strong supporting force for the rest power electronics.

The second PCB is designed for current and voltage measurement. There are five current transducers on board for three phase input current from grid and two input current of three-phase PM machine. Since machine windings are in star connection, two current transducers are employed for machine phase current measurement. Three voltage transducers are employed for three phase grid side voltage measurements to ensure an accurate Phase Lock Loop (PLL). A $120 \mathrm{kHz}$ bandwidth, low distortion, isolation amplifier is employed for DC link voltage measurement due to $750 \mathrm{~V}$ demand.

The third PCB is a 24-channel gate drive board. Just as its name implies, there are 24 channel gate drive circuits arranged on it. Each channel occupies a $15^{\circ}$ sector, and drive signals from Digital Signal Processor (DSP) flow from edge to the center of this board. Finally, 24 isolated $+20 /-5 \mathrm{~V}$ drive signals generate and output to the power board.

The last two boards are AC filter and DC link capacitors. The total length of the power electronics is about $150 \mathrm{~mm}$. Capacitors occupies about half length of the all power electronics. Full lists of main components employed in this drive system are shown in Table III.

TABLE III

\begin{tabular}{|c|c|c|c|}
\hline \multicolumn{4}{|c|}{ Power board } \\
\hline $\begin{array}{c}\text { SiC Power } \\
\text { Switches }\end{array}$ & C2M0040120D & \\
\hline \multicolumn{4}{|c|}{ Transducer board } \\
\hline $\begin{array}{c}\text { Current } \\
\text { transducer }\end{array}$ & LEM LA 100-P & $\begin{array}{c}\text { Voltage } \\
\text { transducer }\end{array}$ & LEM LV 25-P \\
\hline $\begin{array}{c}\text { Isolation } \\
\text { amplifier }\end{array}$ & AD215AY & & \\
\hline \multicolumn{4}{|c|}{ 24-channel gate drive board } \\
\hline $\begin{array}{c}\text { DC:DC } \\
\text { converter }\end{array}$ & MGJ2D152005SC & Opto-coupler & ACPL-P480 \\
\hline $\begin{array}{c}\text { MOSFET } \\
\text { driver }\end{array}$ & IXDN609SI & \\
\hline \multicolumn{4}{|c|}{ DC link capacitor board } \\
\hline $\begin{array}{c}\text { DC link } \\
\text { capacitors }\end{array}$ & B32776T1355 & & \\
\hline \multicolumn{4}{|c|}{ LCL filter capacitor board } \\
\hline $\begin{array}{c}\text { AC capacitors } \\
\text { B B32926H3156 }\end{array}$ & Resolver & TS2225N1112E102 \\
\hline
\end{tabular}

\section{COOLING CONSIDERATION}

Since it highly decouples the cooling system design from the machine electromagnetic design, the jacket cooling has been widely used as a force cooling method in the off-theshelf electrical machine [19]. A water-cooled jacket cooling design is proposed for the IMD here.

As shown in Fig. 10(a), the outer case model has designed 12 terraces for 24 MOSFETs along the radial direction. This design is not merely a cooling consideration but also a mechanical joint solution for power converters and the machine.

The internal coolant channels are shown in Fig. 10 (b). The coolant flows into the jacket from the inlet and splits into 
two streams flowing through two parallel endplate paths. Two streams then flow along the parallel return path snaking along machine axial surface and join at the outlet point. The volume of coolant, liquid flow rates, the restriction pressure and the inlet temperature are calculated and simulated according to a specific chiller. The full assembled IMD is shown in Fig. 11.

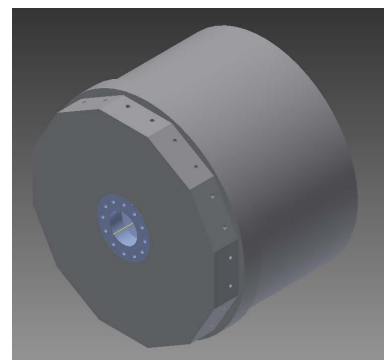

(a) Outer case model

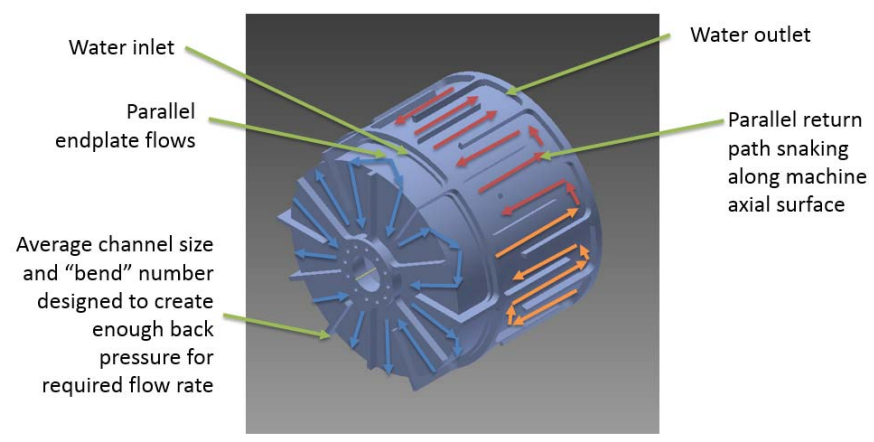

(b) Internal coolant channels

Fig. 10. Full assembled power electronics in the integrated drive.

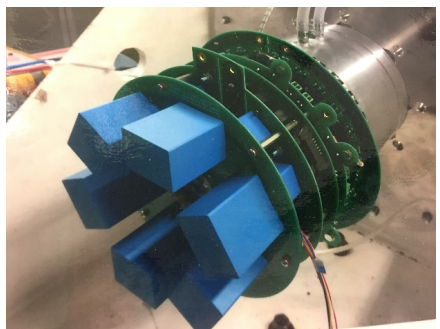

Fig. 11. Full assembled power electronics in the integrated drive.

\section{EXPERIMENTAL VALIDATION}

The testing work of this IMD is still on going. A set of the experimental results are shown in Fig. 12 and Fig. 13. The IMD machine rotates at $3000 \mathrm{r} / \mathrm{min}$ producing $4.0 \mathrm{~N} \cdot \mathrm{m}$ average torque. The LCL filter works effectively, it reduces the THD from $10.51 \%$ to $3.29 \%$ without affecting the normal operation of the PM machine.

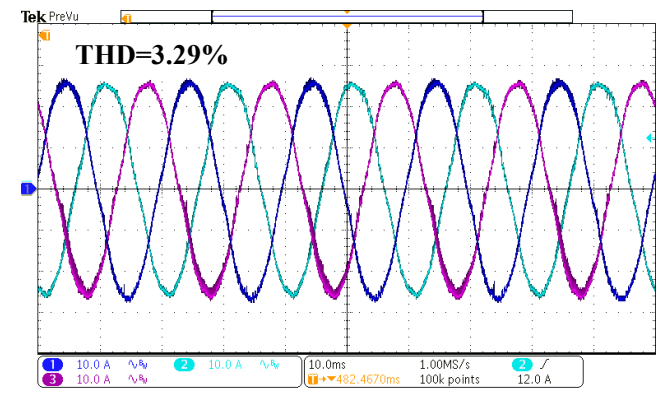

Fig. 12. Grid side three phase current.

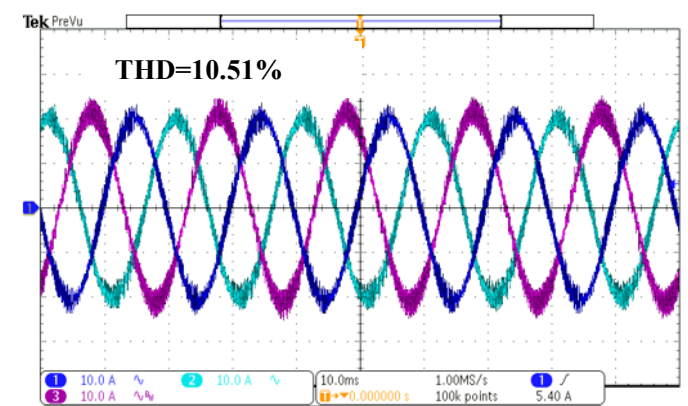

Fig. 13. Rectifier side three phase current.

\section{CONCLUSIONS}

This paper presents a high-speed integrated Permanent Magnet (PM) machine and its drive system. The magnetics of the grid connected LCL filter are integrated in the double slot machine. FE analysis is carried out to find the optimum pole numbers combination having the minimum coupling effects between two inductors in the same phase. Afterwards, a novel 4-layer bus bar solution is proposed to manage extra terminals induced by the LCL filter and all the other electrical connections to the front-end mounted power electronics. A modular functional and structural power electronics design with $\mathrm{SiC}$ MOSFETs is then proposed and constructed. A water-cooled heatsink considering both of the machine and the high power density power electronics is then proposed as the thermal management solution of this IMD. The experimental results show that the integrated LCL filter can effectively reduce the THD.

\section{ACKNOWLEDGMENT}

This work was supported by the Engineering and Physical Sciences Research Council (EPSRC) Centre for Power Electronics (Grant references: EP/K035304/1, $\mathrm{EP} / \mathrm{K} 034987 / 1)$.

\section{REFERENCES}

[1] R. Abebe, G. Vakil, G. L. Calzo, T. Cox, S. Lambert, M. Johnson, et al., "Integrated motor drives: state of the art and future trends," IET Electric Power Applications, vol. 10, pp. 757-771, 2016.

[2] S. M. Lambert, B. C. Mecrow, R. Abebe, G. Vakil, and C. M. Johnson, "2," in 2015 IEEE Vehicle Power and Propulsion Conference (VPPC), 2015, pp. 1-6.

[3] A. Tenconi, F. Profumo, S. E. Bauer, and M. D. Hennen, "Temperatures Evaluation in an Integrated Motor Drive for Traction Applications," IEEE Transactions on Industrial Electronics, vol. 55, pp. 3619-3626, 2008.

[4] R. Abebe, G. Vakil, G. L. Calzo, T. Cox, C. Gerada, and M. Johnson, "FEA based thermal analysis of various topologies for Integrated Motor Drives (IMD)," in IECON 2015 - 41st Annual Conference of the IEEE Industrial Electronics Society, 2015, pp. 001976-001981.

[5] M. März, A. Schletz, B. Eckardt, S. Egelkraut, and H. Rauh, "Power electronics system integration for electric and hybrid vehicles," in 2010 6th International Conference on Integrated Power Electronics Systems, 2010, pp. 1-10.

[6] S. Haghbin, K. Khan, S. Zhao, M. Alakula, S. Lundmark, and O. Carlson, "An Integrated 20-kW Motor Drive and Isolated Battery Charger for Plug-In Vehicles," IEEE Transactions on Power Electronics, vol. 28, pp. 4013-4029, 2013.

[7] S. Haghbin, T. Thiringer, and O. Carlson, "An integrated split-phase dual-inverter permanent magnet motor drive and battery charger for grid-connected electric or hybrid vehicles," in 2012 XXth 
International Conference on Electrical Machines, 2012, pp. 19411947.

[8] C. Klumper, F. Blaabjerg, and P. Thoegersen, "Alternate ASDs: evaluation of the converter topologies suited for integrated motor drives," IEEE Industry Applications Magazine, vol. 12, pp. 71-83, 2006.

[9] M. Liserre, F. Blaabjerg, and S. Hansen, "Design and control of an LCL-filter-based three-phase active rectifier," IEEE Transactions on Industry Applications, vol. 41, pp. 1281-1291, 2005

[10] Y. Liu, K. Y. See, S. Yin, R. Simanjorang, C. F. Tong, A. Nawawi, et al., "LCL Filter Design of a 50-kW 60-kHz SiC Inverter with Size and Thermal Considerations for Aerospace Applications," IEEE Transactions on Industrial Electronics, vol. 64, pp. 8321-8333, 2017.

[11] J. Muhlethaler, M. Schweizer, R. Blattmann, J. W. Kolar, and A. Ecklebe, "Optimal Design of LCL Harmonic Filters for Three-Phase PFC Rectifiers," IEEE Transactions on Power Electronics, vol. 28, pp. 3114-3125, 2013.

[12] J. Millán, P. Godignon, X. Perpiñà, A. Pérez-Tomás, and J. Rebollo, "A Survey of Wide Bandgap Power Semiconductor Devices," IEEE Transactions on Power Electronics, vol. 29, pp. 2155-2163, 2014.

[13] N. Oswald, P. Anthony, N. McNeill, and B. H. Stark, "An Experimental Investigation of the Tradeoff between Switching Losses and EMI Generation With Hard-Switched All-Si, Si-SiC, and All-SiC Device Combinations," IEEE Transactions on Power Electronics, vol. 29, pp. 2393-2407, 2014.

[14] N. R. Brown, T. M. Jahns, and R. D. Lorenz, "Power Converter Design for an Integrated Modular Motor Drive," in 2007 IEEE Industry Applications Annual Meeting, 2007, pp. 1322-1328.

[15] J. Wang, Y. Li, and Y. Han, "Evaluation and design for an integrated modular motor drive (IMMD) with GaN devices," in 2013 IEEE Energy Conversion Congress and Exposition, 2013, pp. 4318-4325.

[16] M. A. Mohamed, S. M. Lambert, B. C. Mecrow, D. J. Atkinson, and A. C. Smith, "An electrical machine with integrated drive LCL filter components," in 8th IET International Conference on Power Electronics, Machines and Drives (PEMD 2016), 2016, pp. 1-6.

[17] X. Deng, S. Lambert, B. Mecrow, M. A. S. Mohamed, and S. Ullah, "Winding connection solution for an integrated synchronous motor drive," in 2017 IEEE International Electric Machines and Drives Conference (IEMDC), 2017, pp. 1-7.

[18] W. M. Haynes, CRC Handbook of Chemistry and Physics, 2016.

[19] A. Tüysüz, F. Meyer, M. Steichen, C. Zwyssig, and J. W. Kolar, "Advanced Cooling Methods for High-Speed Electrical Machines," IEEE Transactions on Industry Applications, vol. 53, pp. 2077-2087, 2017.

\section{BIOGRAPHIES}

Xu Deng received the B.Eng. and M.Eng. degrees in Electrical Engineering from Nanjing University of Aeronautics and Astronautics, Nanjing, China, in 2010 and 2013, respectively. She received the PhD degree in Electrical Engineering from Newcastle University, Newcastle upon Tyne, U.K, in 2017. She is currently a Research Associate of Electrical Power Research Group in the School of Engineering, Newcastle University, Newcastle upon Tyne, U.K. Her main researches are integrated drives and advanced control methods for power electronics and electric machines.

Simon M. Lambert received the M.Eng. (Hons.) degree in electrical and electronic engineering and the Ph.D. degree in electrical engineering from Newcastle University, Newcastle upon Tyne, U.K., in 2008 and 2012, respectively. In 2011, he joined the Electrical Power Research Group, Newcastle University. He is currently a Senior Research Associate presently attached to the EPSRC National Centre for Power Electronics, Nottingham, U.K., via the underpinning power electronics research programme conducting research in the field of electric drives. Since 2011, he has been working on research concentrating on automotive battery management and characterization.

Barrie Mecrow received the Ph.D. degree in Electrical Engineering from Newcastle University, Newcastle, U.K., in 1986. He was a Turbo-generator Design Engineer at NEI Parsons, Newcastle upon Tyne, U.K. In 1987, he became a Lecturer and in 1998 a Professor at Newcastle University. His research interests include fault-tolerant drives, high-performance permanent magnet machines, and novel switched reluctance drives.

Mohamed Awad S Mohamed received Mohamed Awad S Mohamed received the B.Sc. degree in electrical and electronics engineering from Benghazi University, Benghazi, Libya, in 2002. In 2003 was an electrical engineer at North Benghazi Power Generation Plant, GECOL company, Libya. He received the M.Sc. degree from the University of Newcastle Upon Tyne in 2010. He received the grants from GECOL company and Engineering and physical Science Research Council (EPSRC) for his further education in the U.K. in 2014, where he is currently working towards the $\mathrm{Ph} . \mathrm{D}$. degree as a part of the Electrical Power Group, school of engineering. His research interests include the integration of passive components in electrical drives and finite element modelling of electrical machines. 